\title{
VALUE CREATION ELEMENTS IN LEARNING COLLABORATIVE NETWORKED ORGANIZATIONS
}

\author{
Leandro Loss, Alexandra A. Pereira-Klen, Ricardo J. Rabelo \\ Federal University of Santa Catarina, Department of Automation and Systems \\ GSIGMA - Intelligent Manufacturing Systems Group, BRAZIL \\ \{loss,klen\}@gsigma.ufsc.br \\ rabelo@das.ufsc.br \\ Organizations that work in strategic alliances, also known as Collaborative \\ Networked Organizations (CNOs), learn with this experience. The whole \\ learning process in which they are involved with is rich, creates value for the \\ alliance and should be better explored in order to improve the CNO partners' \\ performance when facing new challenges. The core content of this work is \\ related to the characterization of value creation elements that support the \\ learning process in a CNO environment. These elements create value for the \\ entire alliance in the technological, organizational and human perspectives \\ and hence contribute to the learning process and to the preparedness of CNOs.
}

\section{INTRODUCTION}

Approximately over the last ten years several researchers have developed frameworks, reference models, techniques, and tools in order to support business in strategic alliances (Child, 2003). The core idea behind the concept of such strategic alliances, also known as Collaborative Networked Organizations (CNO) (Camarinha-Matos and Afsarmanesh, 2006), is that organizations working together are stronger than when working only by themselves or isolated. As a result organizations may share responsibilities, risks, profits, improve their work power, market share and become more competitive.

At the same time, while such studies evolve, new challenges appear. Actually, the scope and the complexity of related activities have achieved a new degree of complexity when considering inter-organizational operations. Innovative approaches have been developed in order to attend to this emergent need. As a consequence of this rapid development and efficiency improvement, adequate resources and knowledge are required. However, very often resources are not available or there is a lack of adequate knowledge for carrying out inter-organizational tasks which are based on distributed and collaborative business processes.

The fact is that it is very hard to succeed in the establishment of strategic alliances where everything happens according to what was originally planned. There are many variables involved in this context and there is not a single way to predict or to be ready to foresee all possible problems. An important but quite few explored research area is related to the learning capacity that networked organizations intrinsically have. This learning is not only related to the organizational learning perspective of one single organization, but rather it is also related to the learning 
capacity of all partners involved in the alliance. Additionally, other parameters that should be also taken into account refer to the capacity of the entire network to learn with its own experience and with the experience of others, and, even more relevant, the ability to create value to the entire alliance.

In this sense, it is important to advance the literature about learning in strategic alliances towards elements to foster value creation in those alliances. Such value will help to understand partners' behavior, concepts involved in collaboration opportunities, and in cooperation processes. Value creation may also support stronger foundations and the preparedness required to create dynamic alliances, like Virtual Organizations.

Following the idea of Learning based on value creation, three elements are described in this work. This paper is therefore divided as follows: section two presents the concepts of strategic alliances in general, and of Collaborative Networked Organizations, Virtual Organization Breeding Environments, Professional Virtual Communities, and Virtual Organizations in particular. Section three defines the concept of Learning CNOs as well as the characterization of supporting tools and techniques taking the value creation elements into consideration. Finally, section four presents some preliminary conclusions.

\section{STRATEGIC ALLIANCES}

One alternative that has arisen in order to help organizations to become more competitive is to join competences, work power, and knowledge. This may become true via alliances. By definition (Oxford, 2000), an alliance is "an agreement between countries, political parties, etc. to work together in order to achieve something that they all want". It means sharing risks and benefits (profits) when facing new collaboration opportunities. Thus, a strategic alliance (also known as business partnering) may be understood as a formal relationship that grows up between two or more parties to pursue a set of agreed goals or to meet a critical business (Lendrum, 1997). It is important to highlight that during a strategic alliance, participants remain as independent organizations (Doz, 1998).

Strategic alliances are not new in society. They have appeared over the years in many areas, including politics, trade, humanitarian support, among others. However, this field has increased its importance nowadays due to its empowerment by the Information and Communication Technologies (ICT) (Castells, 2006). ICT infrastructures have provided more reliable communication channels and higher interconnectivity between organizations (B2B approaches), between organizations and people (B2C approaches) and even among people by ordinary instant messaging tools.

Strategic alliances also may vary from a vast amount of manifestations. According to Child and Faulkner, (1998) and Child (2003), strategic alliances range from contract-based manifestations (like joint ventures, holdings, consortia) and supply chains (Gaspareto, 2003), to less formal or more dynamic collaboration forms (like Virtual Organizations (VOs) and Virtual Enterprises (Camarinha-Matos et al., 2005).

The discipline that studies such diversity of forms of collaboration is called Collaborative Networks (Camarinha-Matos and Afsarmanesh, 2006), and it 
comprises a variety of entities that includes people, companies or non-profit organizations that are not necessarily settled in the same country or region. They are also largely autonomous and heterogeneous. This heterogeneity also considers different environments and culture of each involved entity (Camarinha-Matos and Afsarmanesh, 2007). According to Camarinha-Matos and Afsarmanesh, (2006), collaborative networks that have some kind of organization (e.g. ethical code, rules, and roles) are called Collaborative Networked Organizations (CNOs).

In the ECOLEAD Project (2006), three main manifestations of CNOs have been more deeply studied, which are Virtual Organizations, Virtual Organizations Breeding Environments, and Professional Virtual Communities.

The term Virtual Organization (VO) is defined indistinctly by many authors. Wassenaar (1999) relates VOs with theories from electronic commerce (e-commerce and e-business). Strausak (1998) considers VOs as informal entities with the participation of many organizations. Others, like Kaihara and Fujii (2006), define VOs as agile and reconfigurable organizations. However, definition for VO that has gained more importance in researches is straightforward related to ICTs infrastructures as they allow overcoming barriers of time and distance among organizations (Eversheim et al., 1998). In this sense Rabelo and Pereira-Klen (2004) define VOs as "temporary alliances among organizations that come together to share skills or core competencies and resources in order to better respond to new collaboration opportunities as well as to produce value-added services and products, and whose cooperation is supported by computer networks". Nevertheless, VOs cannot be easily created from a vast mount of organizations where there is no commitment and well defined rules. In order to support the VO creation and launching phases, and to also give some level of preparedness to the organizations, the concept of VBE has emerged.

Virtual Organization Breeding Environment (VBE) is seen as long term association of service enterprises or organizations that work together in order to overcome other obstacles of communication and distance among organizations and that may be in the way of the rapid formation of VOs (Camarinha-Matos and Afsarmanesh 2004). These obstacles include aspects as trust building, contract establishment, business roles and duties, and even cultural differences among the organizations willing to work as a VO.

In a complementary perspective, the Professional Virtual Communities (PVCs) combine the concepts of virtual teams and professional communities. The former is related to social systems of networks of individuals and the relationships of these individuals are mediated by ICT tools. The latter is related to the ecosystem where the professionals that are taking part of a certain virtual team may share knowledge, have similar working culture, similar values, among others (Camarinha-Matos and Afsarmanesh 2004). It is possible to correlate Virtual Teams with Virtual Organizations, and PVCs with VBEs.

Much has been developed under the umbrella built by these three CNO manifestations. There are the researches related to trust building (Msanjila and Afsarmanesh, 2006), governance rules (Romero et al., 2007), PVCs management (Crave et al., 2006 and Picard, 2007), ICT support (Tramontin-Jr and Rabelo, 2007), and partner search and suggestion (Baldo et al., 2007), VO performance measurement (Westphal et al., 2007), just to mention some approaches. 
Despite all efforts, very few of them have been dealing with the learning issue as well as using it as a way to leverage value creation in CNOs. Next section explores some issues that should be considered in Learning CNO (L-CNO).

\section{LEARNING CNOs}

The concept of Learning Collaborative Networked Organization (L-CNO) is seen as the ability that a $\mathrm{CNO}$ has to gather its experience and its existing and new knowledge for value creation along the CNO's life-cycle. This concept fits better to long-term associations like VBEs and PCVs as knowledge produced by short-term manifestations (like VO) are more volatile and hence more difficult to gather. This means that once VOs are dissolved, the knowledge produced by them can be easily lost or simply remain spread over many partners that have worked together. Even though when VOs emerge from VBEs the problem is that knowledge is usually lost if they are not properly gathered and stored.

The area which has tackled this problem has been called Virtual Organization Inheritance (VO-I) (Loss et al., 2006, Karvonen et al., 2007). VO-I is seen as the process of gathering the information and knowledge from past VOs, whereas VO-I Management is the process that manages what has been inherent about given VOs, usually supported by computer systems, for enhancing the CNO behavior (VBE or PCV) (Loss et al., 2007b). It comprises a continuous improvement of business processes and rules, as well as the quality of the final products and/or services.

However VO-I is not concerned with the learning aspect, neither with the value creation in CNOs. An initial work towards a framework for L-CNO was proposed in a previous work (Loss et al, 2007b), which was based on VO-I foundations combined with Knowledge Management (KM) and Organizational Learning (OL) areas. This framework's goal aimed supporting CNOs to learn and to create value. In that work two main analysis axes were considered: one axe for dealing with organizational value elements, and the other axe with technological value elements.

In the work presented in this paper, this approach is extended with the addition of more aspects as it was restricted to some specific techniques and tools. An extra axe has been incorporated, which is the human value element. Figure 1 shows the proposed extension, presenting the three main value elements for L-CNO.

This considers that value creation elements can be represented by (a set of) tools or mechanisms that leverage $\mathrm{CNO}$ value creation throughout collaboration. These three value creation elements are seen as complementary to each other. It means that L-CNO mechanism is more effective if these three elements are applied together. For example, an organizational procedure may be easier to execute when supported by some computational tool. However, tools do not execute tasks alone, they require human interaction instead. In a complementary perspective, individuals may execute tasks in an easier manner when they have well established rules and procedures. Another important point that is covered by the human value element is the social aspect, which is intrinsically involved in all activities and that impact the CNO learning and value creation. 


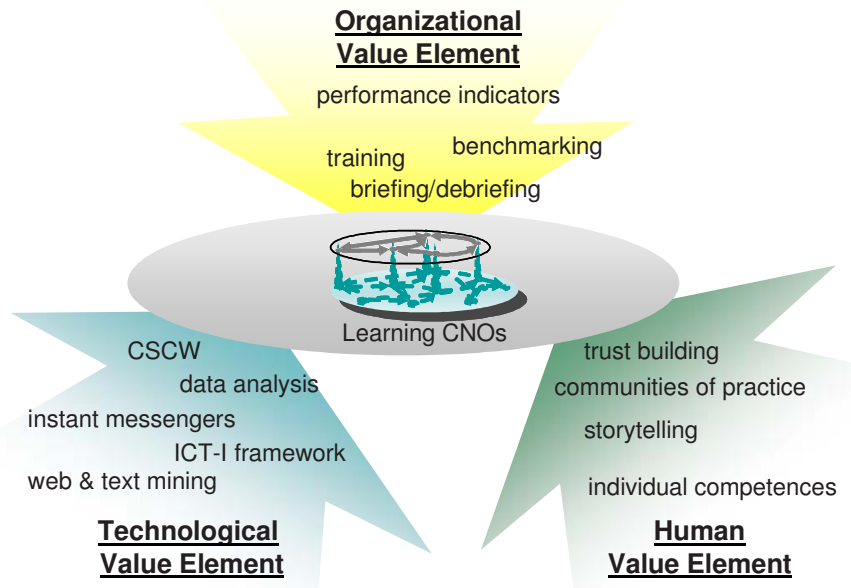

Figure 1 - Value Elements of L-CNO

\subsection{Organizational Value Element}

In the proposed approach, briefing and debriefing mechanisms (Loss et al., 2006) are the VO-I instruments used to implement the Organizational value element. The former comprises a list of duties and responsibilities that are expected to be executed/done during the VO life-cycle. The latter is a counter-check of this list and it is done either during the life-cycle or at the end of the VO. Milestones are checked during the debriefing and the most important issues are recorded. Successful and unsuccessful situations might be noted down for future retrieval. Under the Knowledge Management perspective, briefing and debriefing cover the distribution, creation and evolution of the knowledge (Loss et al., 2007b). It also supports the creation of economic value by reducing costs when saving time and resources with the results of these mechanisms.

Although briefing and debriefing are effective, these mechanisms do not gather all the knowledge produced by short-term alliances. In this way, other methods, techniques, and tools shall be taken into account for the L-CNO environment and value creation. These new approaches may be benchmarking, performance indicators, training programs, among others.

According to Vallejos et al. (2006), benchmarking is a continuous and systematic process used to evaluate enterprises' business processes. It is used in order to establish referential patterns of performance. Likewise briefing and debriefing, evaluations done in benchmarking processes can be stored and the top ranked can become a referential to the other CNO's partners. In this sense, partners may learn with the knowledge produced by CNO throughout the evolution of practices and processes. Value can then be created when new business processes are executed taking advantage of what has been learnt. Benchmarking can also be applied based on organizations out of the CNO's scope, acting as a target to be reached by the entire CNO. Framing benchmarking to the KM approach, it leads to knowledge creation as every time a new referential pattern emerges (the benchmark) 
new approaches on how to behave in face to this arise up. As a result, knowledge evolution takes place. Knowledge is also formalized as new practices are written down and made available to other partners.

Another interesting line that can contribute to L-CNOs is the adoption of performance indicators (PIs) in order to measure CNOs performance (Westphal et al., 2007). In a close approach, Baldo et al, (2007) has proposed a methodology to select the most suitable PIs that should be applied to VO partners' selection for given collaboration opportunities. Similarly to benchmarking, PIs' values are seen as metrics used to quantify processes or objectives. Well formalized PIs represent formalized and organized knowledge. PIs also facilitate knowledge distribution as they can be spread out CNO's members in a standard terminology.

Still about the organizational element, Steil (2006) argues that organizations which promote training programs to their employees are willing to get back what it was invested in terms of productivity, competitiveness, and higher profits. Researches done by Bassi et al. (2000) show that investments on training programs increase the total stockholder return. It is an evidence that what is learned by employees is usually absorbed by the organization since the knowledge gathered by one individual in training activities can be distributed to other partners, fostering the confrontation of experiences and the creation of new knowledge into the CNO. The organizational value element is empowered when supported by tools. Next subsection brings some tools that can be part of L-CNO environment.

\subsection{Technological Value Element}

The technological value creation element considers the tools that support extraction, storing, access, and distribution of information and knowledge to all interested CNO's members. This leverages the $\mathrm{CNO}$ learning by using, spreading, and producing knowledge. In general, the technological creation element comprises ICT Infrastructures (ICT-I). Rabelo et al. (2006) presented a distributed ICT-I model where a set of CNO-related services can be accessed on demand, and some of these services can be used as enablers to support the desired information gathering for the CNO learning.

Another approach is data analysis techniques, such as data mining, which can extract hidden patterns from data within CNOs. Despite this approach is valid only for CNOs that store data in structural repositories (e.g. databases), the analysis of a vast amount of data is a powerful ally in several situations, like checking marketing tendencies, which typical have been occurring in the last VOs, which are the most trustful partners according to the different VOs' types of products, and the generation of understandable hypothesis.

In a similar context, there are tools related to Text and Web Mining (Mladenic and Grobelnik, 2003). Text and Web mining techniques are applied in data sources that neither have predefined formats nor are stored in databases. When these techniques are applied to CNOs, they may provide support for retrieving documents and documents' categorization.

Actually, even simple tools for messages exchange like Windows Live Instant Messenger, Google talk, Skype, Miranda, Pidgn, among others, shall support the CNO's learning and value creation. Despite their simplicity, they provide peer-topeer communication hence they are extremely relevant in exchanging knowledge 
among people instantaneously. Moreover, when history files are stored by users they can be retrieved in the future or also be under analysis of text mining tools (this is, for example, one facility supported by one of the services of that mentioned ICT-I).

A further alternative for fostering CNO learning is the adoption of Computer Supported Cooperative Work (CSCW) tools. These tools are used to coordinate activities among people by the use o computer systems. Besides innumerous applications, these tools can support the creation/elaboration of contracts and facilitate the implementation of electronic contracts (e-contracts). E-contracts also help in defining business activities that are expected to occur as well as sanctions for any deviation from the prescribed behavior. E-contracts are framed in L-CNO because they can be an important type of information from where knowledge can be generated to help in future businesses.

\subsection{Human Value Element}

According to Jonassen (1996), when dealing with organizations, one should not only take care of technological or organizational aspects, but also of their integration with human aspects regarding that individuals are the core of any organization.

With the aim of encouraging the knowledge exchange in an informal way and the trust building, another part of the research described in Loss et al. (2007a) has proposed the use of Communities of Practice (CoPs). The authors argue that CoPs act as a mechanism for trust building among CNO's partners based on the assumption that knowledge is more easily exchanged when done among people who know and trust to each other.

Another interesting strategy is the storytelling technique (Snowden, 2001). It is used for promoting dissemination of knowledge among people, for building trust, and for creating cultural value. Snowden claims that storytelling reveals patterns of culture and behavior about organizations lives and this is a way to manage the communication flow and understanding within an organization. If applied in the context of L-CNO, storytelling can be very useful to disseminate best practices in a CNO due to its easy understanding. According to Brown and Duguid (2001), much of the existing knowledge in working groups (like CNOs) comes from their stories. Brown and Duguid (2001) argue that the constant storytelling about problems, solutions, failures and reasons, and triumphs that happens over breakfast, lunch, and coffee, can also server to a number of purposes and others' situations.

Nevertheless, individual competences shall not be forgotten when considering an L-CNO environment and value creation. Competence is seen a set of knowledge that comprise a certain subject. Competences are extremely linked to the tacit knowledge of each individual, to the individual's abilities (physical or mental) related to certain tasks, to the values, and even to the social relationship with other people around. Whenever people are encouraged to improve their competences, the benefits of this personal growth can reflect in the CNO improvement as well. New forms of acting are absorbed by the CNO throughout people's abilities, knowledge and culture.

As one may note, the human value creation element is closely related to the organizational value creation element, and both are supported by the technological value creation element. These three elements support the value creation in CNOs and are enablers to fostering a Learning $\mathrm{CNO}$ environment. 


\section{CONCLUSIONS}

This paper has presented the key elements for supporting CNOs learning. The involved processes consider three complementary perspectives. Extending a previous work, the organizational and technological value creation elements were improved. Methods and tools such benchmarking, performance indicators, and training programs were added to the organizational value element. For the technological value creation element, tools such as text and web mining, instant messengers, and CSCW were considered. Besides these two value creation elements, a third one was brought up to light: the human value creation element. Its facilitators are composed by communities of practices, trust building, storytelling, and individual competences.

It is important to highlight that the organizational and technological value creation elements shall be seen as a set of mechanisms that may be used to improve the efficiency in disseminating and combining data. When they are merged and properly used by individuals (human value element) they can support the L-CNO concept and create value in/to the entire $\mathrm{CNO}$.

The proposed model provides methodologies and tools that can be used for managing best practices and spreading them out to all CNOs' members, which creates a virtuous cycle of learning and hence enhance CNO competitiveness.

Next steps of this research include the investigation of the influence of corporate governance in learning; the characterization of environments where knowledge can be easily shared; the investigation of the relation learning and $\mathrm{CNO}$; and an empirical study using the framework in a real case.

\subsection{Acknowledgments}

This work has been developed in the scope of the Brazilian IFM project (www.ifm.org.br) and the European IST FP-6 IP ECOLEAD project (www.ecolead.org).

\section{REFERENCES}

1. Bassi, L.; Ludwig, J.; McMurrer, D.; Buren, M.; 2000. Profiting from Learning: Do Firms' Investments in Education and Training Pay Off? Research White Paper. American Society for Training and Development, 2000.

2. Baldo, F.; Rabelo, R. J.; Vallejos, R. V.; An Ontology-Based Approach for Selecting Performance Indicators for Partners Suggestion. In: Establishing the Foundation of Collaborative Networks. Camarinha-Matos, L. M.; Afsarmanesh, H.; Novais, P.; Analide, C.; (eds) Springer, p 187-196.

3. Brown J. S; Duguid, P.; Balancing Act: How to Capture Knowledge without Killing It. In: Harvard Business Review on Organizational Learning. Harvard Business School Publishing Boston, p 45-60.

4. Camarinha-Matos, L. M., Afsarmanesh, H.; 2004. Collaborative Networked Organizations: A Research Agenda for Emerging Business Models. Kluwer Academic Publishers, Norwell, MA, USA.

5. Camarinha-Matos, L. M., Afsarmanesh, H., e Ollus, M.; 2005. Virtual Organizations: Systems and Practices. Springer, Norwell, MA, USA. 
6. Camarinha-Matos, L. M. e Afsarmanesh, H.; 2006. Collaborative networks: Value creation in a knowledge society. In PROLAMAT conference, eds. Wang, K., Kovács, G. L., Wozny, M. J., e Fang, M., volume 207 of IFIP, (Boston: Springer) pp 26-40.

7. Camarinha-Matos, L. M., Afsarmanesh, H.; 2007. A Comprehensive Modeling Framework for Collaborative Networked Organizations. Journal of Intelligent Manufacturing. 18:529-542.

8. Castells, M.; 2006. A Sociedade em Rede, volume 1. Paz e Terra, 9a. edição.

9. Child, J., Faulkner, D., 1998. Strategies of Cooperation. Oxford: Oxford University Press Inc.

10. Child, J.; 2003. Learning Through Strategic Alliances. Eds. Dierkes, M., Antal, A. B., Child, J., e Nonaka, I., Handbook of Org. Learning and Knowledge. Oxford University Press Inc. pp 657-680.

11. Crave, S.; Bouron, T.; Ladame, S.; 2006. Using Social Capital as a Conceptual Framework for Professional Virtual Communites Formalization.. In Camarinha-Matos, L. M., Afsarmanesh, H., e Ollus, M., (eds); Network-Centric Collaboration and Supporting Frameworks. Helsinki, Finland, volume 224. Springer. pp 371-378.

12. Doz Y. L., Hamel G., Alliance Advantage. The art of Creating Value through Partnering, Harvard Business School Press, Boston, 1998.

13. ECOLEAD 2006. European Collaborative Networked Organizations Leadership Initiative. Technical report D21.4a - Characterization of VBE Value Systems and Metrics, March 2006.

14. Eversheim,W., Bauernhansl, T., Bremer, C., Molina, A., Schuth, S., Walz, M.; 1998. Configuration of Virtual Enterprises based on a Framework for Global Virtual Business. In: Sieber, P. and Griese, J., (eds), Organizational Virtualness - VONet - Workshop, pp 77-83, Simowa Verlag. Simowa, Verlag Bern.

15. Gaspareto, V.; 2003. A systematic approach for supply chain performance evaluation [in Portuguese]. PhD Thesis, Department of Production Engineering, Federal University of Santa Catarina, Brazil.

16. Jonassen, D.; 1996. The use of new information technologies in distance education and constructiuve learing [in Portuguese], INEP, pp.16-70.

17. Kaihara, T.; Fujii, S.; 2006. Game theoretic negotiation strategy for virtual enterprise with multiagent systems. In Camarinha-Matos, L. M., Afsarmanesh, H., e Ollus, M., (eds); Network-Centric Collaboration and Supporting Frameworks. Helsinki, volume 224. Springer. pp 439-448.

18. Karvonen, I., Salkari, I., Ollus, M., 2007. Identification of Forms and Components of VO Inheritance. In IFIP International Federation of Information Processing, Volume 243. Establishing the Foundation of Collaborative Networks; eds. Camarinha-Matos, L., Afsarmanesh, H., Novais, P., Analide, C. (Boston: Springer), pp 253-262.

19. Lendrum T., The Strategic Partnering Handbook, A Practice Guide for Managers, McGraw-Hill, Nook Company, 1997.

20. Loss, L., Pereira-Klen, A. A., Rabelo, R. J., 2006. Virtual Organization Management: An Approach Based on Inheritance Information. In: Global Conference on Sustainable Product Development and Life Cycle Engineering.. Oct 03-06. São Carlos, SP, Brazil.

21. Loss, L.; Schons, C. H.; Neves, R.M.; Delavy, I. L.; Chudzikiewicz, I. S.; Vogt, A. M.; 2007a. Trust Building in Collaborative Networked Organizations Supported by Communities of Practices. In: Establishing the Foundation of Collaborative Networks. Camarinha-Matos, L. M.; Afsarmanesh, H.; Novais, P.; Analide, C.; (eds) Springer, pp 23-30.

22. Loss, L.; Pereira-Klen, A. A., Rabelo, R. J.; 2007b. Towards Learning Collaborative Networked Organizations. In: Establishing the Foundation of Collaborative Networks. Camarinha-Matos, L. M.; Afsarmanesh, H.; Novais, P.; Analide, C.; (eds) Springer, pp 243-525.

23. Mladenic, D.; Grobelnik, M.; 2003. Text and Web Mining. In Mladenic, D., Lavrac, N., Bohanec, M., Moyle, S., (eds); Data Mining and Decision Support: Integration and Collaboration. Kluwer Academic Publishers, The Netherlands. pp 15-22.

24. Msanjila, S. S.; Afsarmanesh, H.; 2006. Assessment and Creation of Trust in VBEs. In: NetworkCentric Collaboration and Supporting Frameworks. Camarinha-Matos, L. M.; Afsarmanesh, Ollus, M..; (eds) Springer, pp 161-172.

25. Oxford; 2000. Advanced Learners Dictionary of Current English. Oxford University Press.

26. Picard, W.; 2007. Support For Power in Adaptation of Social Protocols for Professional Virtual Communites. In: Establishing the Foundation of Collaborative Networks. Camarinha-Matos, L. M.; Afsarmanesh, H.; Novais, P.; Analide, C.; (eds) Springer, pp 363-370.

27. Rabelo, R. J., Pereira-Klen, A. A.; 2004. Collaborative Networked Organizations: A Research Agenda for Emerging Business Models, capítulo A Brazilian Observatory on Global and Collaborative Networked Organizations. In Collaborative Networked Organizations: A Research Agenda for Emerging Business Models (eds) Kluwer Academic Publishers, pp 103-112. 
28. Rabelo, R. J., Gusmeroli, S.; Arana, C.; Nagellen, T.; 2006. The ECOLEAD ICT Infrastructure for Collaborative Networked Organizations. In: Network-Centric Collaboration and Supporting Frameworks. Camarinha-Matos, L. M.; Afsarmanesh, Ollus, M..; (eds) Springer, pp 451-460.

29. Romero D.; Galeano, N.; Molina, A..; 2007. A Conceptual Model for Virtual Breeding Environments Value Systems. In: Establishing the Foundation of Collaborative Networks. Camarinha-Matos, L. M.; Afsarmanesh, H.; Novais, P.; Analide, C.; (eds) Springer, p 43-52.

30. Snowden, D.; Narrative Patterns: the perils and possibilities of using story in organizations. In: Knowledge Management. Vol 4, Issue 10, 2001. pp. 3-14.

31. Steil, A. V.; 2006. Competences and Organizational Learning: how to plan training programs to empower organizations to learn form individual competences [in Portuguese]. Stella Institute, Florianópolis - Brazil, $1^{\text {st }}$ edition.

32. Strausak, N.; 1998. Resume of VoTalk. In Sieber, P. and Griese, J., (eds), Organizational Virtualness - VONet - Workshop, pp 9-24, Simowa Verlag. Simowa Verlag Bern.

33. Tramontin Jr., R. J.; Rabelo, R. J.; A Knowledge Search Framework for Collaborative Networks. In: Establishing the Foundation of Collaborative Networks. Camarinha-Matos, L. M.; Afsarmanesh, H.; Novais, P.; Analide, C.; (eds) Springer, pp 573-582.

34. Vallejos, R. V.; Lima, C.; Varvais, G.; 2006. A Framework to Create a Virtual Org. Breeding Environment in the Mould and Die Sector. In: Network-Centric Collaboration and Supporting Frameworks. Camarinha-Matos, L. M.; Afsarmanesh, Ollus, M..; (eds) Springer, pp 599-608.

35. Wassenaar, A.; 1999. Understanding and designing virtual organisation forms. VoNet Newsletter. Vol. 3, No 1, Berne.

36. Westphal, I.; Thoben, K.; Seifert, M.; 2007. Measuring Collaboration Performance in Virtual Organizations. In: Establishing the Foundation of Collaborative Networks. Camarinha-Matos, L. M.; Afsarmanesh, H.; Novais, P.; Analide, C.; (eds) Springer, pp 33-42. 